\title{
Práticas de organização e representação da informação étnico-racial em bibliotecas universitárias: necessidade de preservação da memória de negros
}

\author{
Mirian Albuquerque Aquino \\ miriabu@gmail.com \\ Universidade Federal da Paraíba \\ Vanessa Alves Santana \\ vanessabibliotecaria@gmail.com \\ Universidade Federal da Paraíba
}

Resumo: Em um mundo globalizado em que a informação ganha cada vez mais espaços na sociedade, as práticas de organização, representação e acesso dessas informações ganham uma nova preocupação no que diz respeito aos assuntos voltados para as questões raciais que até então não se evidenciam na prática. Devido a esse fato, os pilares da sociedade da informação-conhecimento-aprendizagem e diante da explosão documental, tem se percebido a necessidade de priorizar a participação positiva de grupos que durante muito tempo são vistos como minorias, tomando posição quanto às práticas de organização e representação da informação frente às novas demandas informacionais e aos interesses de busca de cada indivíduo. A prioridade é de se efetivar o reconhecimento das bibliotecas enquanto lugares constituintes de memória, disseminando informações étnico-raciais capazes de construir imagens positivas exercendo seu papel de servir a comunidade de modo geral e respondendo na prática às demandas da diversidade cultural assumindo assim o compromisso de organizar, representar e disseminar a informação étnico-racial adequadamente.

Palavras-chave: informação étnico-racial; bibliotecas universitárias; inclusão racial.

Abstract: In a globalized world in which information acquires more spaces in society, the practices of organization, representation and access to these pieces of information perform a new viewpoint in relation to issues concerned with racial matters that, so far, are not highlighted in practice. Due to this fact, the cornerstones of information-knowledge-learning society and taking into account the documental burst, the need to prioritize the positive participation of groups that, for so long, are considered minorities has been perceived. This focuses on the position in regard to the practices of organization and representation of information with reference to the new informational demands and to the search interests of each individual. The priority is to accomplish the acknowledgement of libraries as places constituent of memory, disseminating ethnic and racial information able to construct positive images by fulfilling their role of serving the community, in a general way, and answering, in practice, to the demands of cultural diversity assuming thus the commitment to organize, represent and disseminate ethnic and racial information suitably.

Keywords: ethnic-racial information; university libraries; racial inclusion. 


\section{INTRODUÇÃO}

As tecnologias intelectuais ${ }^{1}$ em sua velocidade e instantaneidade da informação tornam irreversivelmente obsoletas uma grande parte das estruturas políticas, econômicas, sociais e culturais no mundo de hoje. Os grandes conglomerados da indústria, economia e comunicação colocam a necessidade de se aplicar, eficazmente, as tecnologias intelectuais em diversos setores para o desenvolvimento das sociedades e comunidades do mundo inteiro, considerando que estamos em um cenário cada vez mais complexo que exige eficiência, produtividade e competitividade. Com efeito, os países em desenvolvimento priorizam teoricamente a participação e a inclusão das pessoas no cenário da informação, conhecimento e comunicação, mas sabemos que se trata de um discurso que não se efetiva na prática.

Essa nova ordem informacional estabelece-se positivamente no que concerne à aplicação qualitativa das tecnologias intelectuais ao desenvolvimento das nações, sociedades e indivíduos, perspectivando a redução das barreiras responsáveis por criarem um fosso entre os que têm informação e os que não têm informação. Em razão disso, a sociedade brasileira, afetada pelo "dilúvio de informação", põe em relevo a urgência de "contrapor-se ao risco de ruptura entre uma minoria privilegiada e uma maioria despreparada com a interposição do divisor digital" (TEDESCO, 2004, p. 7).

As sociedades abertas e globais, construídas "sobre novos valores, novos marcos, novos modos de vida e novas prioridades" (HALÉY, 2010, p. 9) e "entendidas como aquelas que se caracterizam pela produção intensiva de conhecimento e pela gama de serviços pósindustriais produzidos", exigem dos sujeitos as "competências de acesso, avaliação e gestão da informação oferecida" (ALARCAO, 2003, p. 12). Essas exigências colocam a ciência, a tecnologia, a pesquisa, a educação e a informação como fatores insubstituíveis nas transformações (GONZALEZ DE GOMEZ, 2011) das sociedades contemporâneas. Em decorrência dessas mutações, o sujeito precisa estar capacitado "para assumir a globalidade, a fluidez, a rapidez e a imprecisão das situações e dos processos complexos" (HALÉY, 2010, p. 15).

Entretanto, quem estiver desprovido de informação e conhecimento enfrenta uma crise que cerca a estrutura contemporânea das novas relações de trabalho e a competição no expansivo mercado das atividades profissionais. Diante disso, é necessário ter a compreensão de que homens e mulheres (negros, brancos, amarelos etc) "não são nem iguais, nem desiguais, nem de fato, nem de direito: são irredutivelmente diferentes em seu ser, em suas

\footnotetext{
${ }^{1}$ Conceito utilizado por Lèvy (2003).
} 
aspirações, em seus talentos, em suas necessidades" (HALÉY, 2010, p. 120) e, para concretizar esses atributos, essa diversidade cultural precisa estar adequadamente inserida nesse novo contexto em que a informação e o conhecimento assumiram novos papéis.

O novo cenário requer uma educação que se preocupe com o desenvolvimento do ser humano não apenas em sua dimensão científico-tecnológica, mas também como condutora de culturas e valores inerentes à formação integral dos sujeitos. È imprescindível implementar políticas públicas mais encorpadas e processos de capacitação para profissionais da informação, a fim de que possam dinamizar e atualizar as atividades de informação, oferecidas pelas escolas, universidades, museus, bibliotecas e arquivos, visando a adaptação às mudanças e a ruptura com o modo habitual dos profissionais da informação exercerem suas práticas.

Essa responsabilidade gravita em torno de um conjunto de tensões que força a redefinição do papel da Ciência da Informação nas práticas de organização e representação da informação cujo acesso pelos usuários sempre foi difícil ao longo da história. Desde a invenção da escrita, a parte mais valiosa e interessante da informação esteve depositada em textos acessíveis a um pequeno grupo de pessoas. Dessa forma, a Ciência da Informação, enquanto espaço de formação de profissionais da informação e de produção de conhecimento, tem a responsabilidade ético-social de contribuir com a atualização das práticas de organização e representação da informação visando solucionar problemas que afetam aqueles que necessitam de informação.

Essa área de conhecimento tem o potencial de oferecer as condições de acesso e uso da informação para ajudar a reduzir uma "parte considerável do desnível entre indivíduos, organizações, regiões, países (BRASIL, 2000) e comunidades que dependem de informação para o reconhecimento de seus territórios, pertencimento, identidades, histórias e culturas. Na visão de Zaoual (2003, p. 21), "essas tensões e recomposições são a raiz da afirmação das identidades e dos territórios. Em todos os lugares, cada vez mais as pessoas sentem necessidade de crer e se inserir em locais de pertencimento".

Em meio a essas tensões, as instâncias informacionais (escolas, universidades, bibliotecas, museus, arquivos e centros de documentação, dentre outros) ainda não assumiram a responsabilidade de eliminar as distorções nas práticas de organização e representação da informação que, consciente ou inconscientemente, excluem os saberes produzidos por diferentes grupos (negros, indígenas, homossexuais, deficientes etc) que compõe a nossa sociedade reconhecida hoje como multicultural. Os grupos que precariamente estão conseguindo entrar na geografia urbana brasileira pressionam os diversos setores para disponibilizarem a informação nos diferentes meios de comunicação e nos suportes 
tecnológicos, a fim de afirmar seu "pretenso sentimento de pertencimento" (KOUBI, 2004, p. 531) nessa sociedade que se caracteriza como democrática.

Por sua vez, as universidades públicas federais são questionadas em suas responsabilidades e funções. De um lado, acusam-na de estar na origem das exclusões sociais e raciais agravando o "desmantelamento do tecido social" (DELORS, 1999) e, de outro, visualizam-na como uma instituição que clama pelo restabelecimento da igualdade racial na perspectiva de uma educação como um direito de todos os cidadãos independente da crença, raça/etnia, sexo etc. Entretanto, tal compreensão não se realiza na prática (AQUINO, 2011).

Em torno das bibliotecas universitárias circulam pesquisas que sugerem o abandono das práticas de organização e representação da informação, voltadas prioritariamente para a cultura eurocêntrica em detrimento da cultura afrocêntrica, cuja existência é permeada por diferentes culturas e grupos em uma mesma sociedade (ROSAS, 2007); (SANTANA, 2012) “onde convivem inúmeras etnias e que já não são mais aceitos só os conhecimentos proporcionados pela visão de mundo eurocêntrica" (PRAXEDES, 2012).

Conhecer a cultura afrocêntrica é importante para o profissional da informação se conscientizar de que as práticas de organização e representação da informação não estão isentas das constantes pressões dos novos usuários que adentram as universidades públicas federais e buscam a informação de diversos tipos e modalidades com a finalidade de investigar temas específicos para a construção de uma nova história, vez que estamos imersos em uma sociedade preconceituosa, discriminatória e racista, incidindo em incertezas, receios e inseguranças. São tempos líquidos (BAUMAN, 1995). Em tempos líquidos, é importante chamar a atenção do profissional-bibliotecário para as necessidades de informação que exigem as qualidades de adaptação, mobilidade, flexibilidade, competência, habilidade, informação e conhecimento para lidar com a informação.

Nessa linha de discussão, Tedesco $(2004$, p. 25$)$ afirma que o problema "na atualidade não é encontrar a informação, mas como oferecer acesso a ela sem exclusão, e ao mesmo tempo, aprender e ensinar a selecioná-la, avaliá-la, interpretá-la, classificá-la e usá-la". Diante disso, a construção de um novo perfil do profissional-bibliotecário para agir dinamicamente nas práticas de organização e representação da informação nos sistemas tecnológicos das bibliotecas universitárias prescinde do compromisso com as transformações econômicas, sociais, políticas e culturais que estão ocorrendo no mundo.

O profissional-bibliotecário deve ser competente com uma formação flexível e contextualizada; ser reflexivo e crítico no campo de sua atividade profissional e de investigação; estar aberto às mudanças, ao novo, ao diálogo, à ação cooperativa na sua relação com os usuários; ser exigente na interpretação crítica da informação e da sociedade de seu 
tempo; ser interativo possibilitando ao aluno desenvolver-se integralmente nas dimensões cognitiva, afetiva, social, moral, física, estética (MERCADO, 2012).

Sendo assim, com as recentes mutações socioculturais aumentaram a responsabilidade de gestores dos cursos de Biblioteconomia, Arquivologia e Ciência da Informação no sentido de investirem densamente na formação contínua dos profissionais do presente e do futuro para renovarem suas práticas de organização e representação da informação visando a preservação da memória não apenas dos saberes eurocêntricos, mas também dos saberes afrocêntricos de modo a tornar mais visível a riqueza cultural da ancestralidade africana e afrodescendente, bem como dos demais grupos excluídos da sociedade brasileira.

\section{AS BIBLIOTECAS UNIVERSITÁRIAS COMO LUGARES DE MEMÓRIA}

As bibliotecas podem ser reconhecidas como lugares da memória que "guardam materialmente a memória de um povo, de uma cidade, de um país" (DRUMOND; CARELLI, 2008), organizam e representam os "verdadeiros lugares da história", mas esquecem o que ancestrais negros e descendentes ${ }^{2}$ produziram ao longo de sua história, visando preservar a memória do seu povo. Essa "memória encontra-se, assim, prisioneira da história ou encurralada nos domínios do privado e do íntimo, transformou-se em objeto e trama da história, em memória historicizada" (SEIXAS, 2004, p. 41) .

A memória do povo negro e outras memórias [...] transitam pelo apagamento de outras memórias na afirmação impositiva da interpretação unívoca de acontecimentos e orientações políticas conflituosas" (BRESCANI, 2004, p. 13 [...]. Esquecer a memória de intelectuais negros é uma dívida histórica que " não se limita a guardar o rastro material, escrito ou outro, dos fatos acabados, mas entretém o sentimento de dever a outros, dos quais diremos mais adiante que não são mais, mas já foram.

Pagar a dívida, diremos, mas também submeter a herança a inventário (RICOEUR, 2007, p. 101) dos bens econômicos e sociais que foram sonegados. Para Le Goff (1990), “[...] não podemos esquecer os verdadeiros lugares da história, aqueles onde se deve procurar, [...] os criadores e os denominadores da memória coletiva: Estados, meios sociais e políticos, comunidades de experiências históricas ou de gerações, levadas a constituir os seus arquivos em função dos usos diferentes que fazem a memória (LE GOFF, 1990, p. 473).

\footnotetext{
${ }^{2}$ Guerreiro Ramos, Clóvis Moura, Abdias do Nascimento, André Rebouças, Luis Gama, Cruz e Souza, Dandara, Lélia Gonzáles,Luiza Mahin Milton Santos, Kabengele Munanga, Carlos Moore, Henrique Cunha Júnior, Petronilha Gonçalves e Silva, Valter Silvério, Nilma Lino Gomes, José Rufino, Solange Rocha Pereira, Elio Flores, José Antônio Novaes da Silva, Alba Cleide Calado Wanderley, etc.
} 
Por sua vez, Orlandi (2012, p. 169) converge para o pensamento de Ricouer enfatizando que "o esquecimento é constitutivo da memória [e] estruturante do funcionamento da memória". Contudo, "para que haja memória, é preciso que o acontecimento ou o saber registrado saia da indiferença, que ele deixe o domínio da insignificância ( PÊCHEUX, 1999, p. 25) a fim de poder posteriormente fazer a impressão". È certo que as bibliotecas, os museus, os arquivos e os centros de documentação reconhecidos como "lugares de memória" (NORA, 1993) não podem esquecer o Outro, porque “esquecimento é dano, fraqueza e lacuna” (RICOUER, 2007, p. 424).

Diante desse quadro, não podemos esquecer que os negros estão privados do acesso a informação que the interessa e impedidos de terem a oportunidade de competir em iguais condições com os brancos historicamente privilegiados, e formam a elite dominante de nosso país. Mudar tal situação "depende ainda, de trabalho conjunto, de articulação entre processos educativos escolares, políticas públicas, movimentos sociais, visto que as mudanças éticas, culturais, pedagógicas e políticas nas relações étnico-raciais não se limitam à escola" (BRASIL, 2003, p. 13).

\section{PRÁTICAS DE ORGANIZAÇÃO E REPRESENTAÇÃO DA INFORMAÇÃO}

As bibliotecas universitárias ainda reproduzem um passado herdado do Império Romano em que os detentores do poder usaram a censura para defender a Religião, o Estado e a Moral para favorecer seus ideais e manter a autoridade nos conventos e nas bibliotecas tradicionais. Antes criadas para serem coadjuvantes do desenvolvimento das sociedades da época e satisfazerem as necessidades dos usuários que a procuravam e clamavam por informação, essas bibliotecas tradicionais passam a ser objetos de repressão, proibição, controle e fiscalização na organização e representação da informação.

No século XIII, o exercício da censura começa a funcionar no momento em que os textos aristotélicos chegam à Universidade de Paris, (HAROCHE, 1992). Nesse contexto, eclode um movimento universitário em que as autoridades eclesiásticas começam a perceber a existência de "uma concepção de mundo atuante nos escritos aristotélicos, abertamente, contraditória em relação ao ensino da Igreja" (HAROCHE 1992, p. 60).

Ao mesmo tempo, as autoridades eclesiásticas começam a ver que "a coexistência de uma verdade baseada na fé com uma outra baseada na razão corre o risco de colocar em perigo, mais rapidamente a autoridade da Igreja" (HAROCHE 1992, p. 60). De acordo com Haroche (1992) está claro que a censura para os clérigos era o instrumento de coerção importante porque 
a Igreja apóia-se com efeito na doutrina de uma verdade única e universal, da qual o sujeito religioso não poderia ter senão um conhecimento parcial. A existência de várias doutrinas concorrentes, até mesmo contraditórias, de um pluralismo logo percebido como ambigüidade doutrinal, arrisca enfraquecer a ordem religiosa $e$, conseqüentemente, as formas de dominação que ela exerce sobre o indivíduo. A ordem é até então imposta ao indivíduo no quadro de uma ordem de estruturas fortemente hierarquizadas (HAROCHE, 1992, p. 60).

Importa considerar que as práticas de censura no Brasil foram exercitadas nas bibliotecas conventuais durante o Período Colonial, como ocorreu nas irmandades de São Bento, de São Francisco, das Carmelitas, dos Franciscanos e dos Beneditinos (OLIVEIRA, 2012). A partir daí, a censura descortina no momento em que "a proibição de Pombal de que fundassem novos conventos e a instituição do ensino leigo diminuem o papel dos conventos na formação intelectual dos jovens e, em fins do século XVIII, não representavam mais o que representavam antes" (MORAES, 1979, p. 19).

Essa proibição fez com que os conventos passassem a exercer um papel secundário na educação brasileira, desestabilizando o poder da Igreja (OLIVEIRA, 2012). Ademais, os ideais de laicização, democratização, especialização e socialização, a ruptura dos laços com a Igreja Católica e a pretensão de estender "a todos os homens a possibilidade de acesso aos livros" (MARTINS, 2001) e/ou a informação não foram suficientes para a biblioteca moderna redefinir coerentemente as suas práticas.

As práticas bibliotecárias ocultam uma parte da história que traz um fato importante para a reconstrução da história de nosso país. Certamente, elas desconhecem que os afrodescendentes continuam honrando seus ancestrais africanos com a ativação de uma memória que luta contra o esquecimento através da "resistência social". Ao redor dessa questão, o Movimento Negro, os ativistas e intelectuais negros mobilizam ações concretas junto ao Governo Brasileiro para impedirem que a memória do povo africano e afrodescendente continue sendo fraturada pelos resquícios da colonização e do escravismo criminoso. Trata-se de libertar a memória desse povo que ainda continua sendo interpelada pela violação dos direitos, humilhação sutil, degradação moral e lesão psíquica que deterioraram a sua dignidade humana (HONNETH, 2003).

Essa deteriorização torna-se presente quando observamos que os profissionaisbibliotecários dificilmente aplicam os mesmos parâmetros utilizados nas práticas de organização e representação da informação étnico-racial, justificando, simbolicamente, que os temas de interesse de africanos e afrodescendentes não pertencem aos construtos universais 
ou ao eurocentrismo ${ }^{3}$. Essas práticas caracterizam-se como processo de exclusão que elege uma língua universal e exprime um conhecimento desvinculado das necessidades de informação específica que o usuário busca.

Apesar da internet ter aberto uma nova perspectiva de crescimento da informação na prática bibliotecária, o usuário ainda depara com dispositivos coercitivos na prática bibliotecária que limitam o acesso e uso da informação étnico-racial e suprimem a sua verdadeira relação com o conhecimento. É importante ressaltar que os próprios sistemas de classificação mobilizados pelas bibliotecas universitárias se ocupam da função de "esquecer ou apagar" determinados tipos de informações e utilizar alguns tipos de classificações invisíveis para serem acessadas somente por eles, eliminando a liberdade dos leitores ou usuários. Sobre essa questão, Chartier (1994, p. 37) afirma que "a liberdade do leitor de ter acesso ao livro está sempre inscrita no interior de dependências múltiplas, mas também em condições de ignorar, deslocar ou subverter os dispositivos destinados a reduzí-la".

Essas práticas de organização e representação da informação sugerem uma ausência de sensibilidade de não "querer dizer" (HAROCHE, 1992) ou não querer reconhecer a mudança do modelo centrado na informação para o modelo centrado no usuário (FIGUEIREDO, 1999). Com isso, quer nos parecer que este último modelo não serve como norte para expansão cognitiva dos profissionais que atuam nas bibliotecas universitárias. A partir desse ponto, as práticas de organização e representação da informação atravessam uma tradição orientada não pela estrutura do sistema, mas sim pelas concepções de mundo, sistema, biblioteca, formação profissional e ideologia dos sujeitos (profissionais-bibliotecários).

Embora não tenhamos a intenção de desqualificar a prática desses profissionais, é importante dizer que não conseguiram plenamente sorver os enormes avanços propiciados pelas "tecnologias da inteligência" (LÈVY, 1993). È evidente que não perceberam devidamente a presença de novos sujeitos sociais concretos reivindicando políticas públicas que visem à correção e à superação das desigualdades raciais e as injustiças históricas para conseguirem acesso e permanência de homens e mulheres de diferentes etnias, orientações sexuais, pessoas com deficiência e geracionais nas universidades públicas federais, pois que " são esses sujeitos que, articulados em lutas sociais, movimentos sociais e comunitários, sindicatos etc. politizam o seu lugar na sociedade e denunciam o trato desigual que historicamente lhes têm sido reservado (BRASIL, 2012). Eles enfrentam cotidianamente "contextos de dominação, injustiça, intolerância religiosa, discriminação e desigualdade, sobretudo na educação" (BRASIL, 2012).

\footnotetext{
${ }^{3}$ È a idéia de que a cultura européia é referência mundial, útil e verdadeira (PRAXEDES, 2008).
} 
Portanto, a presença dos novos sujeitos nessas universidades requer também uma biblioteca que atenda temas que tratem coerentemente a diversidade cultural brasileira. Sobre essa questão Robredo (2004) afirma que "as bibliotecas universitárias não se propuseram [...] ainda estabelecer uma doutrina, uma filosofia, se assim pode-se dizer, sobre como proceder no processamento técnico dos documentos e da informação neles contidas e suas relações com os diferentes grupos sociais" (ROBREDO, 2004, p. 23).

Embora saibamos que a finalidade da biblioteca universitária é disponibilizar a informação à comunidade acadêmica não é ético omitir a informação que interessa ao público em geral (movimentos sociais, movimentos negros, movimentos feministas etc). Se a reconhecemos essa Instituição como espaço do saber, onde as inteligências produzem conhecimento para acesso e uso para a diversidade cultural, ela pode ser comparada à “inteligência coletiva" pensada por Lévy (1998): "encontra-se distribuída por toda a parte [...] cuja base e o objetivo [...] são o reconhecimento e o enriquecimento mútuo das pessoas [pois] ninguém sabe tudo, todos sabem alguma coisa, todo o saber está na humanidade" (LÉVY, 1998, p. 30).

Essa compreensão de prática exercida pela biblioteca universitária voltada para todos os grupos sociais implica a criação e a implementação de uma política de informação antidiscriminatória e antirracista, devendo seus profissionais reconhecer que estamos na época dos direitos do homem, cidadão, criança, trabalhador e etnias (CAMBI, 1999). È a época do direito à informação independente dos tipos, formatos e modalidades que interessa a diversidade cultural.

Na verdade, a pretensão da biblioteca universitária de servir à comunidade acadêmica não responde na prática às demandas da diversidade cultural brasileira que chega às universidades públicas federais, e deseja desenvolver atividades de ensino, pesquisa e extensão sobre temáticas específicas. Como afirmam Morigi e Souto (2005), atualmente os usuários têm necessidades muito específicas e o bibliotecário poderia auxiliá-los a filtrar o que realmente eles desejam. Porém, nem sempre ela se encontra devidamente preparada para satisfazer os usuários.

Tem razão Barthes (1987) ao revelar que "a Biblioteca é infinita, na medida em que ela está aquém ou além da procura: tendencialmente, o livro desejado nunca está lá, ao passo que nos é proposto um outro livro" (BARTHES, 1987, p.37). Se isso acontece, com a informação étnico-racial, esta só vai figurar significativamente nos sistemas de informação, se os pesquisadores negros assumirem o compromisso de elaborar e encaminhar listas de material para as bibliotecas com vistas à aquisição de livros, periódicos, dicionários, e-book etc, bem como orientar monografias, dissertações e teses e encaminhá-las para esses espaços. 
Percebendo as necessidades de informação dos usuários, coube a T. Eliot fazer indagações a esse respeito e mencionadas por Robredo $(2004$, p. 3): "Onde estão os documentos que se perderam nos arquivos? Onde estão os livros que se perderam nas bibliotecas? Onde estão os dados que se perderam nos computadores?"

Essas questões postas por T. Eliot inspira-nos a indagar: onde estão as informações que abordam as questões de gênero, etnia/raça, geração, religião, orientação sexual, deficiência etc? Tal pergunta é pertinente porque a biblioteca universitária apresenta uma contradição: "pressupõe uma entidade prestando serviços ao público em geral, independentemente das condições sociais, educacionais e culturais" (SUAIDEN, 2000, p. 57). Contudo, ela não atende a contento as necessidades de informação dos usuários que buscam informação para seus temas e grupos específicos. Sendo assim, as bibliotecas acabam perdendo cada vez mais prestígio e poder diante dos novos meios de acesso, recuperação e uso da informação e deixando de figurar-se como grande centro de apropriação, organização, representação, disseminação e democratização da informação para acesso e uso de um público que a procura.

Isso impossibilita que estudos e pesquisas sobre a temática étnico-racial em cursos de graduação e de pós-graduação nas universidades públicas federais brasileiras alcancem resultados satisfatórios. Embora Araújo, Tenório e Farias (2012) afirmem que "os estudos sobre os temas mais pesquisados apresentam diferenças de um estudo para o outro em uma mesma década, pois refletem as grandes modificações sofridas pela área e que atingem, também, as atividades de pesquisas", essa produção de conhecimento ainda é mínima pelo menos no que se refere às fontes de informação (livros, coletâneas, periódicos, dissertações, teses, comunicações apresentadas em eventos etc).

Remontando a história do Curso de Mestrado em Biblioteconomia (CMB) da UFPB, apesar de ter desenvolvido estudos e pesquisas sobre os fatores sociais que condicionam o desempenho das bibliotecas junto a comunidades de baixa renda na cidade de João Pessoa, não identificamos nenhuma produção de conhecimento sobre a temática étnico-racial. Em 1997 ao ser designado como Curso de Mestrado em Ciência da Informação (CMCl), área de concentração "Informação e Sociedade" e linhas de pesquisa "Informação e Cidadania" e "Informação para o Desenvolvimento Regional, é que surge a primeira dissertação de mestrado defendida em 1999. Entretanto, ao que nos parece o descredenciamento desse Curso em 2000 obstaculizou o aparecimento de novos estudos e pesquisas sobre essa temática, impedindo que a temática étnico-racial se tornasse objeto de investigação de pesquisadores e estudantes.

A partir de 2001, com a chegada de novos pesquisadores interessados nessa temática, começa a surgir o primeiro projeto de iniciação científica e monografias de estudantes no 
Curso de Graduação em Biblioteconomia. Em 2007, a temática ganha força com a criação do novo Programa de Pós-graduação em Ciência da Informação (PPGCI) e as linhas de pesquisa "Memória, Acesso e Organização da Informação" e de "Ética, Gestão e Políticas de Informação". Mesmo tendo essa produção de conhecimento avançado nesses últimos, e até as superado as demais áreas nos programas de pós-graduação na UFPB, os alunos muitas vezes não aprofundam a discussão sobre a temática étnico-racial nas suas dissertações e por conta da insuficiência de uma bibliografia adequada.

No Brasil, os negros que conseguem ingressar nas universidades públicas federais têm dificuldades de encontrar a informação étnico-racial para suprir suas necessidades intelectuais e culturais. Também os pesquisadores-negros são interditados em seu propósito de "descolonizar as ciências, retomando visões de mundo, conteúdos e metodologias de que a ciência ocidental se apropriou, acumulou e a partir deles criou os seus próprios, deixando de mencionar [...] as bases africanas" (GONÇALVES E SILVA, 2003, p. 49).

Para estudantes africanos e afrodescendentes que já estão nessas universidades, é difícil conviver com "procedimentos de exclusão" (FOUCAULT, 2006) de sua história e cultura na organização e representação da informação étnico-racial. Eles convivem, quase sempre, com o estigma da inferioridade, a falta de competência e habilidade para ocupar as funções de prestígios nos diversos setores na atual sociedade brasileira porque, como afirma Praxedes (2008), "continuamos a acreditar na supremacia das culturas, formas de conhecimento, comportamentos e aparência apresentados pelos membros das civilizações européias".

Entretanto, como afirma Cardoso (2011), “[...] mesmo sendo escassas as teorias que acreditam na possibilidade da biblioteca pública contribuir para transformação da cultura, ela também é capaz de impulsionar e de criar mecanismos de oposição ao sistema e favorecer o resgate da memória e da cidadania da população brasileira", sobretudo africanos e afrodescendentes.

Em conversas informais com alunos, professores e pesquisadores, registramos algumas queixas sobre a escassez da informação étnico-racial na Biblioteca Central e nas Bibliotecas Setoriais da UFPB. Os alunos testemunham que encontram dificuldades na busca de informação étnico-racial para elaboração de suas monografias, dissertações e teses, artigos, comunicações etc. Com efeito, essa lacuna provoca sérios entraves para a fundamentação teórico-metodológica de estudos e pesquisas importantes "não apenas para antropólogos, sociólogos, historiadores, militantes, professores e estudantes, mas para todos aqueles que não aceitam desigualdades e discriminação de qualquer natureza" (NASCIMENTO, 2008, p. 30).

A historiografia oficial pouco registra a dura realidade imposta aos africanos pelo regime colonialista em mais de três séculos de escravidão. Quase sempre as narrativas 
históricas produzem/reproduzem um imaginário pobre e preconceituoso, trazendo uma informação étnico-racial desatualizada, extremamente alienante e fortemente restritiva. Há vários livros que fazem referência aos africanos "como pertencentes a raças e etnias misteriosas, donas de comportamentos selvagens, idéias atrasadas, costumes e religiões primitivas e bizarras, aparência horripilante e idéias irracionais [...]" (MUNANGA, 2004, p.24). Frequentemente, aparecem nesses livros imagens de africanos acorrentados e castigados em um tronco. A terra dos macacos, dos leões, dos homens nus, sem civilidade são as representações construídas sobre África (CUNHA JÚNIOR, 2011) nos livros didáticos.

\begin{abstract}
Um problema [...] em relação ao eurocentrismo é que algumas modalidades de conhecimento, autores e obras denominados como "clássicos", já chegam às instituições universitárias brasileiros legitimadas simplesmente porque pertencem a um conjunto de saberes que comporiam aquilo que contemporaneamente vem sendo tratado como o "cânone ocidental". É importante, pois, questionarmos as reivindicações de universalidade das manifestações culturais européias e contestarmos as narrativas e demais produções intelectuais eurocêntricas dominantes na universidade brasileira, como bem demonstram os autores e obras estudados nos cursos de licenciatura e na parte mais representativa dos programas de pósgraduação desenvolvidos em nosso país (PRAXEDES, 2008).
\end{abstract}

Diversos autores da literatura clássica escreveram suas idéias sem considerar as doutrinas filosóficas, a teoria racial, as justificações da escravidão e a defesa da exploração colonial. Homens da ciência, versados nas filosofias naturalistas e darwinistas, profundos conhecedores das teorias raciais e admiradores das idéias de pesquisadores franceses, muito influenciaram o pensamento social brasileiro (PRAXEDES, 2008); (AQUINO; SILVA, 2009).

Sociólogos, biólogos, historiadores, antropólogos, etnólogos, críticos literários ${ }^{4}$ e, não menos, por sacerdotes, artistas, viajantes e colonizadores, assinalaram as suas intenções de classificar os negros a partir de uma escala de valores pouco condizente com a natureza, o desenvolvimento do ser humano e os objetivos de promoção da igualdade racial (AQUINO; SILVA, 2009).

Na história das ciências, o olhar enviesado sobre o Outro fluiu também nos lugares de prestígio. Disciplinas como Sociologia e Antropologia nasceram com a preocupação de compreender o negro como exótico, primitivo, não-branco, proveniente de uma cultura estrangeira menos civilizada (LINCOLN; DENZIN, 2007). Os estudos etnográficos iniciais partiram da "suposição de que os povos primitivos [..] na opinião dos ocidentais eram menos

\footnotetext{
${ }^{4}$ Hume, Kant, Voltaire, Hegel, Comte, Durkheim, Roger Bastide, Florestan Fernandes, Jacob Gorend, Fernando Henrique Cardoso, Octavio lanni, Viotti, Darwin, Linée, Oliveira Vianna, R.Varnhagen, Gilberto Freyre, Malinowiski, Nina Rodrigues, Lèvy-Strauss, Sílvio Romero e Euclides da Cunha.
} 
civilizados do que eles eram, na verdade, réplicas vivas da grande corrente do ser que ligava o ocidente aos seus princípios pré-históricos" (VIDICH; LYMAN, 2007, p.50).

Esses estudos chegaram às universidades e institutos de pesquisa. Para Debus (2011) existem instituições universitárias, onde "os estudos sobre literatura e ensino são um fazer recente e os estudos sobre a temática étnico-racial nos livros infantis e juvenis são mais recentes ainda". Em sua análise sobre livros didáticos de Língua Portuguesa, Silva (2008) afirma que

\begin{abstract}
a despeito de intensa movimentação no campo da produção dos livros didáticos, do tema racismo nos livros didáticos ter participado na agendas das políticas educacionais no Brasil contemporâneo, das avaliações promovidas pelo Ministério da Educação/MEC, o livro didático continua é veiculando discurso racista [...] que universaliza a condição do branco, tratando-o como representante da espécie, naturaliza a dominação branca e estigmatiza o personagem negro, situando-o como out-group, mantendoo circunscrito a determinadas temáticas e espaços sociais (SILVA, 2008, p. 199).
\end{abstract}

As narrativas encontradas nas obras de alguns autores brasileiros rebaixam a autoestima dos negros $\mathrm{Na}$ literatura, o racismo aparece em vários momentos da narração ou descrição de obras que lemos durante a vida escolar. Recentemente um parecer do Conselho Nacional de Educação (CNE) ${ }^{5}$ considerou racista a obra "Caçada de Pedrinho" de autoria de Monteiro Lobato. Também o cartunista Ziraldo desenhou uma camiseta representando a figura de Lobato, na qual uma mulata sambava para um bloco carnavalesco. Este incidente resultou em manifestações e protestos. Analisando essa questão, Sodré (2011) realça as qualidades de Monteiro Lobato, mas afirma que esse autor "[...] era um racista confesso, seu ódio aos negros não é nada que se deduza por interpretação de seu texto ficcional. Mas quase todo o mundo leitor sabe disso. É lamentável fingir inocência ou alegar que o racismo brasileiro é diferente, é "afetuoso" (SODRÉ, 2011). Na visão deste autor, os racismos de Lobato "não são tão numerosos assim em sua obra ficcional, mas estão lá para quem se dispuser a bem enxergar". Ele afirma que "a escrita é um "processo indireto de fazer eugenia" (SODRÉ, 2011).

O modo de escrever empurra negros para estatísticas da desinformação, ignorando a sua real participação na construção, desenvolvimento e formação da cultura brasileira. Sendo assim, a dificuldade para "a recuperação, a escamoteação e a falta de referências sobre a história e a cultura africana desembocam no desconhecimento de suas raízes, que são

9 BRASIL. Ministério da Educação. Conselho Nacional de Educação. Parecer CNE/CEB no 15/2010. Orientações para que a Secretaria de Educação do Distrito Federal se abstenha de utilizar material que não se coadune com as políticas públicas para uma educação antirracista. Brasília: MEC, 2010. Disponível em: $<$ http://portal.mec.gov.br/index.php?option=com_docman\&task=doc_download\&gid=6702\&ltemid=>. Acesso em: 30 maio 2011. 
também as raízes brasileiras" (NASCIMENTO, 2008, p. 14). Pata tentar minimizar essa questão, Sodré (2011) afirma: "o que se pode inicialmente fazer é fornecer algum material para uma reflexão, que talvez possa mesmo contribuir junto aos editores de nossa mídia para a adoção de posições mais qualificadas no tocante à difícil questão racial brasileira".

\section{POR UMA INFORMAÇÃO ÉTNICO-RACIAL}

A expressão "étnico-racial" desvincula-se do termo raça ${ }^{6}$, este entendido como "a construção social forjada nas tensas relações entre brancos e negros, muitas vezes simuladas como harmoniosas, nada tendo a ver com o conceito biológico de raça cunhado no século XVIII e hoje sobejamente superado" (BRASIL, 2003, p. 13). É importante salientar que essa expressão "serve para marcar que essas relações tensas devidas a diferenças na cor da pele e traços fisionômicos o são também devido à raiz cultural plantada na ancestralidade africana, que difere em visão de mundo, valores e princípios das de origem indígena, européia e asiática" (BRASIL, 2013, p. 13).

A antropóloga Nilma Lino Gomes afirma que os intelectuais vêm utilizando o termo "etnia" para se referir aos negros em detrimento ao termo "raça" com o propósito de desvincular do determinismo biológico que divide as raças superiores e raças inferiores.. O uso do termo "raça" foi muito utilizado na área das ciências, na biologia, nos meios acadêmicos, no poder político e na sociedade, mas essa maneira de pensar já foi abolida pela biologia e pela genética Também teve relações com a dominação político-cultural de africanos em detrimento dos europeus, de nações e tribos em detrimento de outras. Ela diz que esse termo acarretou tragédias contra vários grupos sociais e étnicos (GOMES, 2005). Porém, "o termo raça foi ressignificado pelo Movimento Negro que, em várias situações, o utiliza com um sentido político e de valorização do legado deixado pelos africanos". (BRASIL, 2013, p. 13).

Para mudar essa situação, segundo Gomes, o uso do termo "etnia" ganhou força para se referir aos judeus, indígenas, negros, entre outros, com a finalidade de enfatizar que os grupos humanos não eram marcados por características biológicas herdadas dos seus pais, mães e ancestrais, mas, sim, por processos históricos e culturais. A partir desse entendimento, a etnia é o outro termo usado para se referir ao pertencimento ancestral e étnico/racial dos negros e de outros grupos na sociedade brasileira.

Gomes concorda com o pensamento de Cashmore (2000) que define o termo "etnia" como "um grupo possuidor de algum grau de coerência e solidariedade, composto por pessoas

\footnotetext{
${ }^{6} \mathrm{O}$ termo raça é utilizado com freqüência nas relações entre negros e brancos para informar as características físicas (cor de pele, tipo de cabelo, entre outras) que influenciam, interferem e determinam o destino e o lugar social dos sujeitos no interior da sociedade brasileira (BRASIL, 2003).
} 
conscientes, pelo menos em forma latente, de terem origens e interesses comuns" (CASHMORE, 2000, p. 196). Esse autor explica que "um grupo étnico não é mero agrupamento de pessoas ou de um setor da população, mas uma agregação consciente de pessoas unidas ou proximamente relacionadas por experiências compartilhadas" (CASHMORE, 2000, p. 196). Dialogando com Bobbio (1992), Gomes concorda que um grupo étnico é aquele que se define "pela comunidade de língua, cultura, tradições, monumentos históricos e territórios" (BOBBIO, 1992, p. 449) e esclarece que as diferenças "são construções sociais, culturais e políticas entre outros grupos étnico-raciais, nos diferentes contextos internacionais" (GOMES, 2005, p. 51).

A associação da expressão étnico-racial com a informação interessa ao povo africano e afrodescendente brasileiro e tem o propósito de gerar conhecimento oriundo da cultura afrocêntrica que deveria estar presente nos livros, projetos, monografias, dissertações e teses etc das bibliotecas de todos os tipos, formatos, modalidades e características, a fim de se adaptarem às mudanças atuais. Essa informação étnico-racial pode ser entendida como qualquer artefato cultural inscrito em um suporte físico, caracterizado pelo formato tradicional ou digital e passivo de significação pelos sujeitos que o utilizam (OLIVEIRA, 2010).

Para Oliveira, essa informação tem o potencial de produzir conhecimento sobre os elementos históricos e culturais oriundos de um grupo étnico na perspectiva de afirmação de sua identidade e da diversidade humana. Ampliando o conceito proposto por Oliveira, entendemos por informação étnico-racial um legado filosófico, antropológico, sociológico, histórico, geográfico, cultural, religioso, científico, tecnológico da ancestralidade negra e de seus descendentes, raramente é encontrado nos repositórios físicos e virtuais.

Essa informação étnico-racial é aqui discutida na perspectiva positiva da cultura afrocêntrica que, muitas vezes, é ensinada, de forma equivocada, nas escolas e universidades. Não se trata de pretender desqualificar a cultura eurocêntrica, mas, sim, ampliar a concepção de organização e representação da informação para suprir "os interesses da diversidade cultural, racial, social e econômica brasileira [e] incluir as contribuições histórico-culturais de todos os povos" (BRASIL 2003, p.17).

\section{CONSIDERAÇÕES FINAIS}

A ausência da informação étnico-racial reforça a perda de sentido do tempo, espaço e controle dos saberes, da cultura, da história e da memória do povo africano. Portanto, as bibliotecas têm o compromisso de organizar e representar a informação étnico-racial adequadamente, pois não cabe só a escola e a universidade "a responsabilidade de acabar 
com o modo falso e reduzido de tratar a contribuição dos africanos escravizados e de seus descendentes para a construção da nação brasileira" (BRASIL, 2003, p. 18).

A informação étnico-racial nessas bibliotecas ainda permanece limitada, ocultando a visibilidade do negro, a sua contribuição para a sociedade brasileira. È conhecido que a luta do Movimento Negro Brasileiro que resultou na implementação da Lei 10.696/2003 tornou obrigatório o ensino da cultura africana e afrodescendente nos currículos escolares, nas disciplinas, na produção de livros didáticos etc. Contudo, essa lei ainda não conseguiu responder às necessidades do povo negro na busca pela informação étnico-racial, mas continuam a conviver numa relação desigual nas universidades públicas federais.

È prudente que as Políticas de Ações Afirmativas sejam incorporadas "de maneira sistemática na gramática política, acadêmica, jurídica e educacional brasileira" (GOMES, 2008, p. 115 nas universidades públicas federais, a fim de corrigir as desigualdades e neutralizar uma "realidade marcada por posturas subjetivas e objetivas do preconceito, racismo e discriminação [contra negros] que, historicamente, enfrentam dificuldades para acesso e a permanência nas escolas" (BRASIL, 2004).

A (in) visibilidade da informação étnico-racial constrange alunos, professores, pesquisadores, técnico-administrativos e ativistas do movimento negro que conseguem com muito esforço ingressar nas universidades públicas federais. Ao buscar essa informação, esse segmento depara com poucos títulos disponíveis nas bibliotecas universitárias para atenderem suas necessidades informacionais. Em decorrência disso, a frustração dos usuários aumenta por não conseguirem encontrar a informação que procura.

Pesquisadores da linha de "Memória, Acesso e Organização da Informação", Núcleo de Estudos e Pesquisas em Informação, Educação e Relações Étnico-Raciais (NEPIERE) e do Grupo de Estudos Integrando Competências, Construindo Saberes e Formando Cientistas (GEINCOS) produzem conhecimento através de atividades de estudos, pesquisas, orientações e eventos, tendo como resultado livros, coletâneas, artigos, dissertações, comunicações, eventos etc para consolidação da informação étnico-racial. Porém, essa produção que fortaleça a informação étnico-racial nas bibliotecas, sobretudo, da UFPB, ainda é mínima.

\section{REFERÊNCIAS}

ALARCÃO, Isabel. Professores reflexivos em uma escola reflexiva. São Paulo: Cortez, 2003.

AQUINO, Mirian de Albuquerque. Informação, Conhecimento e Memória: processos de apropriação, organização, disseminação e democratização da informação no Movimento Negro da Paraíba. João Pessoa, 2011. Projeto (Pesquisa Científica) - Centro de Ciências Sociais Aplicadas, Universidade Federal da Paraíba. 
ARAÚJO, Eliane Alvarenga de: TENÓRIO, Jovana Karla Gomes; FARIAS, Simarle Nóbrega. A Produção de Conhecimento na Ciência da Informação: analise das dissertações produzidas no Curso de Mestrado em Ciência da Informação -CMCI/UFPB. Disponível em:< http://www.eca.usp.br/nucleos/pc/artigo/eliany_enancib5.pdf>. Acesso:02 jan. 2008.

BARTHES, Roland, O rumor da língua. Lisboa: Edições 70, 1987.

BRASIL, Ministério da Educação. Diretrizes curriculares nacionais para a educação das relações Étnico-raciais e para o ensino de história e cultura afro-brasileira e africana. Brasília: Secretaria Especial de Política de Promoção da Igualdade Racial, 2005. Disponível em: <http://portal.mec.gov.br/cne>. Acesso em: 13 mar. 2012.

BRASIL, CONAE 2010. Conferência Nacional de Educação. Construindo o Sistema Nacional Articulado de educação: o plano nacional de educação, diretrizes e estratégias de ação

BRESCANI, Stella; NAXARA, Márcia Apresentação. In:

Memória e (res) sentimento: indicações sobre uma questão sensível. Campinas: Unicamp, 2004.

BOBBIO, Norberto. A era dos direitos. Rio de Janeiro:Campus, 1992.

BAUMAN, Zigmunt. Vidas despedaçadas. Tradução Carlos Alberto Medeiros. Rio de Janeiro: Jorge Zahar Editor; Rio de Janeiro, 2005.

CAMBI, Franco. História da Pedagogia. Tradução de Álvaro Lorencini. São Paulo: Editora da Universidade de São Paulo, 1999.

CARDOSO, Francilene do Carmo. A biblioteca pública na (re) construção da identidade negra. 2011. 89 f. Dissertação (Mestrado em Ciência da Informação) - Universidade Federal Fluminense, Instituto Brasileiro de Informação em Ciência e Tecnologia, 2011.

CHARTIER, Roger Chartier. A ordem dos livros: leitores, autores e bibliotecas na Europa entre os séculos XIV e XVIII. Brasília: Editora Universitária da UnB, 1994.

CASHMORE, Ellis. Dicionário das Relações étnicas e Raciais. Tradução de Dinah Klave. São Paulo: Summus, 2000.

CUNHA JÚNIOR, Henrique. CUNHA JR. Henrique - A História Africana. In, ROMÃO, Jeruse; LIMA, Ivan C. (orgs) -Negros e Currículos. Florianópolis. Cadernos NEN, no 2, 1997. 111 p. cap. 4. 55-75 p.

DEBUS, Eliane Santana Dias. Caçadas de Pedrinho, de Monteiro Lobato e o parecer do CNE: reflexões. In: CONGRESSO INTERNACIONAL DA ABRALIC: CENTRO, CENTROS - ÉTICA, ESTÉTICA, 12., 2011, Curitiba. Anais eletrônicos... Curitiba: UFPR, 2011. Disponível em: <http://www.abralic.org.br/anais/cong2011/AnaisOnline/resumos/TC0143-1.pdf>. Acesso em: 10 jan. 2012.

DELORS, Jacques. Educação: um tesouro a descobrir. São Paulo: Cortez, 1999.

FIGUEIREDO, Luciana de Conceição. Bibliotecários e racismo: uma análise a partir do parecer 15/2010 do CNE. In: CONGRESSO BRASILEIRO DE BIBLIOTECONOMIA, DOCUMENTAÇÃO E CIÊNCIA DA INFORMAÇÃO: Sistemas de Informação, Multiculturalidade e Inclusão Social, 14., 2011, Maceió. Anais eletrônicos... Disponível em: <http://febab.org.br/congressos/index. php/cbbd/xxiv/paper/view/193/678>. Acesso: 12 fev. 2012. 
FOUCAULT, Michel. A ordem do discurso. Tradução Laura Fraga de Almeida Sampaio. São Paulo: Loyola, 1996.

GOMES, Nilma Lino. Alguns termos e conceitos presentes no debate sobre relações racisias no Brasil: uma breve discussão. In: BRASIL. Ministério da Educação. Secretaria de educação continuada, alfabetização e diversidade. Educação anti-racista: caminhos abertos pela Lei Federal n. 10.639/03. Brasília: Ministério da educação, Secretaria de Educação Continuada, Alfabetização e Diversidade, 2005.

GONÇALVES E SILVA, Petronilha Beatriz. Negros na universidade e produção do conhecimento. In: Gonçalves e Silva, Petronilha Beatriz; Silvério, Valter Roberto (Orgs.). Educação e ações afirmativas: entre a injustiça simbólica e a injustiça econômica. Brasília: Instituto Nacional de Estudos e Pesquisas Educacionais Anísio Teixeira, 2003.

GONZALEZ DE GOMEZ, Maria Nélida. A universidade e a sociedade da informação. Rev. Dig. Bibl. Ci. Inf., Campinas, v.9, n.1, p.225-242, jul./dez. 2011 - ISSN 1678-765X

HALÉY, Marc. A era do conhecimento: princípios e reflexões sobre a revolução noética no século XXXI. São Paulo: UNESP, 2010.

HAROCHE, Claudine. Fazer dizer, querer dizer. Tradução Eni Pulcinelli Orlandi. São Paulo Hucitec, 1992.

HONNETH, Axel. Luta por reconhecimento: a gramática moral dos conflitos sociais. São Paulo: Editora 34, 2003.

INFOBIBLIO. Pesquisa documental. 2009. Disponível em: $<$ http://artedepesquisar.blogspot.com/2009/04/pesquisa-documental.html>. Acesso em: 10 jan. 2012.

KOUBI, Geneviève. Entre sentimentos e ressentimento: as incertezas de um direito das minorias. In: BRESCIANI, Stella; NAXARA, Márcia (Orgs.). Memória e (res)sentimento: indagações sobre uma questão sensível. Campinas: Editora da Unicamp, 2004.

DENZIN, N. K.LINCOLN, Y. S.O planejamento da pesquisa qualitativa: teorias e abordagens. Porto Alegre: Artmed, 2006.

LÉVY, Pierre. As tecnologias da inteligência: o futuro do pensamento na era da informática. Rio de Janeiro: Ed. 34, 1993 (Coleção TRANS).

LÉVY, Pierre. A inteligência coletiva: por uma antropologia do ciberespaço. São Paulo: Loyola, 1998.

MARTINS, Wilson. A Palavra Escrita: história do livro, da imprensa e da biblioteca. 3. ed. São Paulo: Ática, 2001.

MERCADO, Luís Paulo Leopoldo. Formação docente e novas tecnologias. In: CONGRESSO IBEROAMERICANO DE INFORMÁTICA NA EDUCAÇÃO, REALIZADO EM BRASÍLIA-DF, 4., 1998, Maceió. Anais... Maceió: UFAL, 1998. Disponível em: <http://phoenix.sce.fct.unl.pt/ribie/cong> Acesso em: 10 fev.2011.

MONTEIRO, Silvana Drumond; CARELLI, Ana Esmeralda. Ciberespaço, memória e esquecimento. Disponível em: <http://www.enancib.ppgci.ufba.br/artigos/GT1--104.pdf >Acesso em: 12 mar. 2012. 
MORAES, Rubens Borba de. Livros e Bibliotecas no Brasil Colonial. Rio de Janeiro: LTC, 1979.

MORIGI, Valdir José; SOUTO, Luzane Ruscher. Entre o passado e o presente: as visões de biblioteca no mundo contemporâneo. Revista ACB, vol. 10, n. 2, 2005. Disponível em: $<$ http://revista.acbsc.org.br/index. php/racb/article/viewArticle/432/551>. Acesso: 6 jan. 2011.

MUNANGA, Kabengele. A difícil tarefa de definir quem é negro no Brasil (entrevista). Estudos Avançados, São Paulo, v. 18, n. 50, jan./abr. 2004.

NASCIMENTO, Washington Santos. São Domingos, o grande São Domingos: repercussões e representações da Revolução Haitiana no Brasil escravista (1791-1840). Dimensões: Revista de História da UFES, Espírito Santo, n. 125, v. 21, 2008.

NORA, Pierre. Entre a memória e a história: a problemática dos lugares. Projeto História, nำ10, p. 7-28, dez, 1993.

OLIVEIRA, Andréa Carvalho. Direito à memória das comunidades tradicionais: organização de acervo nos terreiros de candomblé de Salvador, Bahia. Ci. Inf., Brasília, v. 39 n. 2, p.84-91, maio/ago., 2010.

OLIVEIRA, Henry Pôncio Cruz de. Afrodescendência, memória e tecnologia: uma aplicação do conceito de informação etnicorracial ao projeto "A Cor da Cultura". 2010, 138 f. Dissertação (Mestrado em Ciência da Informação) - Centro de Ciências Sociais Aplicadas, Universidade Federal da Paraíba, João Pessoa, 2010.

ORLANDI, Eni Pulcinelli. Discurso e homossexualidade: a construção de formas sujeitos. Disponível em: http://www.filologia.org.br/ixfelin/trabalhos/pdf/28.pdf. Acesso: 12 mar. 2012.

PECHÊUX, Michel. Papel da memória. Tradução e Introdução José Horta Nunes. Campinas: Pontes, 1999.

PRAXEDES, Walter. A questão racial e a superação do eurocentrismo na educação escolar. Revista Espaço Acadêmico, n. 89, 2008. Disponível em: http://www.espacoacademico.com.br/089/89praxedes.htm. Acesso: 12 março 2012.

PRAXEDES, Walter. Eurocentrismo e racismo nos clássicos da filosofia e das Ciências Sociais. Revista Espaço Acadêmico, n. 83, abr. 2008. Disponível em: <http://www.espacoacademico.com.br/083/83praxedes.htm> Acesso em: 13 jun. 2011.

RICOEUR, Poul. A memória, a história, o esquecimento. Campinas: Editora Universitária/ UNICAMP, 2007.

ROBREDO, Jaime. Organização dos documentos ou organização da informação: uma questão de escolha. DataGramaZero: Revista de Ciência da Informação, v. 5 n. 1 fev. 2004 Disponível em:

<http://dici.ibict.br/archive/00000345/01/Organização_dos_documentos_ou_organização_da _informação.pdf> Acesso: 13 fev. 2011.

ROSAS, João Cardoso. Sociedade multicultural: conceitos e modelos. In: SEMINÁRIO DIVERSIDADE E IDENTIDADE NACIONAL NA UNIÃO EUROPEIA: DESAFIOS MULTICULTURAIS, 2007, Lisboa. Anais eletrônicos... Lisboa: UNL, 2007. Disponível em: <http://www.ipri.pt/eventos/pdf/PE_JCR_site.pdf>. Acesso em: 06 mar. 2012. 
SANTANA, Vanessa Alves. A responsabilidade social dos profissionais da informação e inclusão de negros/as afrodescendentes: um desafio para bibliotecários da Universidade Federal da Paraíba- UFPB. João Pessoa, 2008. Trabalho de Conclusão de Curso (Graduação em Biblioteconomia). Universidade Federal da Paraíba- Centro de Ciências Sociais Aplicadas. João Pessoa, 2008.

SAUIDEN, Emir José. A biblioteca pública no contexto da sociedade da informação. Rev. Ci. Inf., Brasília, v. 29, n.2, p. 52-60, mai/ago. 2000. Disponível em: <http://www.scielo.br/pdf/ci/v29n2/a07v29n2.pdf Acesso: 11 fev. 2011.

SEIXAS, Jacy Alves. Percursos de memórias em terras de história: problemáticas atuais. In: Memória e (res) sentimento: indicações sobre uma questão sensível. Campinas: Unicamp, 2004.

SILVA, Alba Lígia de Almeida; AQUINO, Mirian de Albuquerque Aquino. Produção de conhecimento escrita por homens sem (cons) ciência da responsabilidade ét(n) ico-social. 2011. Texto digitalizado.

SILVA, Paulo Vinicius Baptista da. Racismo em livros didáticos: estudo sobre negros e brancos em livros de língua portuguesa. Belo Horizonte: Autêntica, 2008.

SODRÉ, Muniz Sodré. Racismo"afetuoso": Monteiro Lobato vai para o trono? Pambazuka news: vozes pan-africanas para a liberdade e justiça, ediçao 36, 2001. Disponivel em: <http://pambazuka.org/pt/category/comment/71411> Acesso: 12 jan 2012.

SUAIDEN, Emir José. A biblioteca pública no contexto da sociedade da informação. Revista Ciência da Informação, Brasilia, v. 29, n. 2, p. 52-60, mai/ago. 2000. Disponível em: <www.revista.ibict.br/index.php/ciinf/article/download/252/220> Acesso: 25 out. 2010.

TEDESCO, Juan Carlos (Org). Educação e novas tecnologias: esperanças ou incerteza? São Paulo: Cortez, 2004.

VIDICH, Arthur J; LYMAN, Stanford M. Métodos qualitatitivos: sua história na soiologia e na antropologia. In: DENZIN; LINCOLN. O planejamento da pesquisa qualitativa: teoria e abordagens. Porto Alegre: Bookman, 2007. 